\title{
Descrição da fêmea de Cladonota amazonica (Andrade) e a distribuição geográfica da espécie (Hemiptera, Auchenorrhyncha, Membracidae)
}

\author{
Gabriel Simões de Andrade ${ }^{1}$
}

\begin{abstract}
Description of the female of Cladonota amazonica (Andrade) and the geographical distribution of the species (Hemiptera, Auchenorrhyncha, Membracidae). Description of the female and notes on the geographical distribution of Cladonota amazonica (Andrade, 1978) are presented.

KEY WORDS. Hemiptera, Auchenorrhyncha, Membracidae, Cladonota, taxonomy
\end{abstract}

Cladonota amazonica (Andrade, 1978) foi descrita com base em dois exemplares machos, procedentes de Sinop, Mato Grosso e Tefé, Amazonas, Brasil. Como ocorre dimorfismo sexual entre as espécies do gênero, não foi possível, até o momento, associar exemplares fêmeas aos machos desta espécie. Examinou-se quatro machos, uma fêmea e três exúvias, coletados sobre Siparuna guianensis (Monimiaceae) na localidade de Moji-Guaçu, São Paulo e pertencentes ao Prof. Benedito Cortês Lopes (Florianópolis, Santa Catarina) (BCL) que possibilitaram o reconhecimento da fêmea, que descrevemos a seguir. Examinou-se também, material pertencente à coleção particular "Carlos Alberto Campos Seabra", Rio de Janeiro, Estado do Rio de Janeiro (CACS), ora incorporada ao Museu Nacional do Rio de Janeiro, e à coleção de Entomologia "Pe. Jesus Santiago Moure", Departamento de Zoologia, Universidade Federal do Paraná, Curitiba, Paraná (DZUP), que amplia a distribuição geográfica da espécie também para os Estados do Pará e Goiás.

Cladonota amazonica (Andrade, 1978)

Figs 1-2

Sphongophorus amazonicus Andrade, 1978: 1.

Cladonota amazonica; McKamey, 1997: 7; McKamey, 1998: 190.

Descrição. Fêmea. Proporções maiores. Coloração geral e forma do pronoto, com exceção do processo pronotal anterior, idênticas as do macho. Processo pronotal anterior recurvado, sinuoso, ultrapassando o ápice das tégminas; terço proximal comprimido ântero-posteriormente; terço médio fortemente comprimido lateralmente, porém com as carenas laterais bem evidenciadas; terço distal achatado dorso-ventralmente; ápice distintamente bilobado.

Material examinado. BRASIL, Amazonas: Manaus (Reserva Ducke), 29.XII. 1976, N.D. Penny leg., 1 fêmea (DZUP). Pará: Castanhal, VII.1984, B. Silva leg., 1 macho (CACS); Tucuruí, I.1983, B. Silva leg., 1 fêmea (CACS). Mato Grosso:

1) Universidade Estadual do Oeste do Paraná, Centro de Ciências Biológicas e da Saúde. Rua Universitária 2069, Caixa Postal 711, 85814-110 Cascavel, Paraná, Brasil.

E-mail: gsa@ certto.com.br 

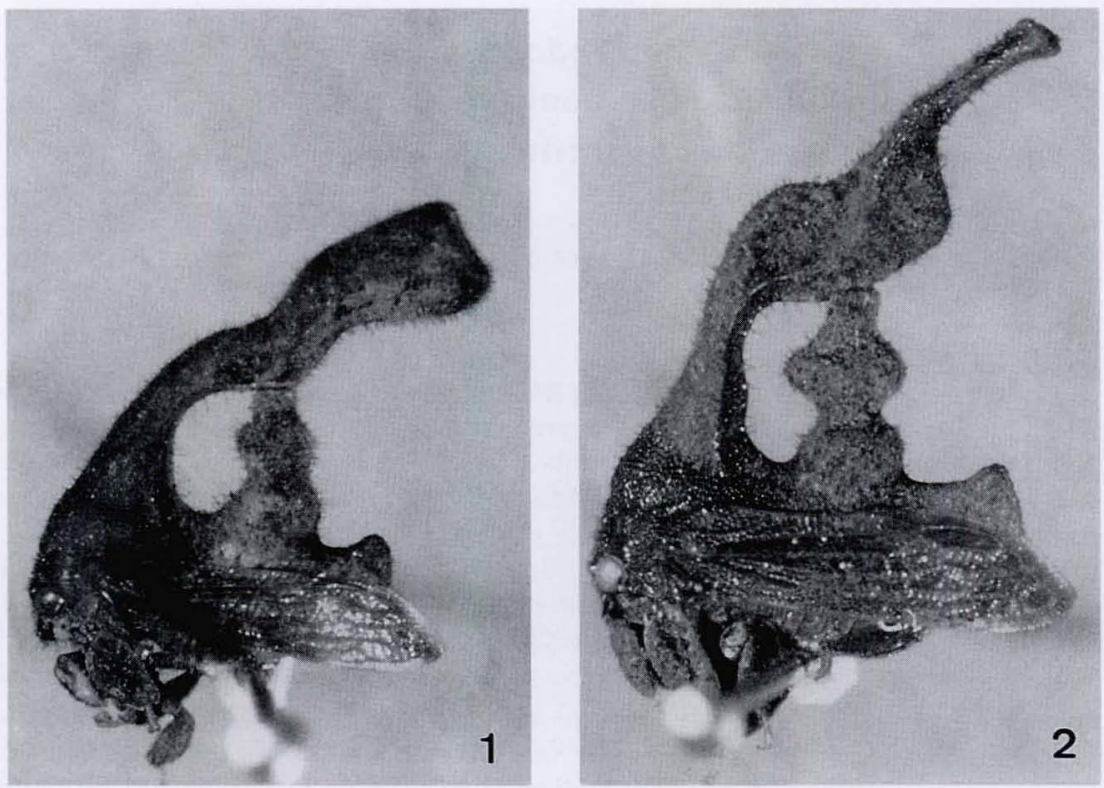

Figs 1-2. Cladonota amazônica: (1) macho, vista lateral direita; (2) vista lateral direita. Fotografias invertidas por motivo de montagem dos exemplares.

Sinop, X.1975, M. Alvarenga leg., 1 macho (DZUP; holótipo); Barra do Bugres, XII.1983, B. Silva, J. Becker \& O. Roppa leg., 1 fêmea (CACS). Goiás: Jataí, XI.1971, F.M. Oliveira leg., 1 fêmea (DZUP). São Paulo: Moji-Guaçu, Estação Experimental de Moji-Guaçu, 13.V.1981, B.C. Lopes leg., 4 machos, 1 fêmea e 3 exúvias, em Siparuna guianensis (Monimiaceae) (BCL).

Comentários. Assim como referido na descrição original do macho, a fêmea também é semelhante à $C$. gracilis (Sakakibara, 1971), descrita do Paraná. Difere por seu porte maior e mais robusto, pelo maior desenvolvimento do processo pronotal anterior, com o ápice distintamente bilobado e pela conformação peculiar da elevação dorsal do processo pronotal posterior.

\section{REFERÊNCIAS BIBLIOGRÁFICAS}

ANDRADE, G.S. 1978. Uma nova espécie do gênero Sphongophorus Fairmaire, 1846 (Homoptera:

Membracidae). Bol. Mus. Paraense Emílio Goeldi, n.s., Zoologia, 93: 1-6.

MCKameY, S.H. 1997. Nomenclatural changes in the Membracidae and Aetalionidae (Hemiptera:

Membracoidea): species-group names and Sphongophorus Fairmaire, revised status. Steenstrupia 22: 1-11.

1998. Taxonomic Catalogue of the Membracoidea (Exclusive of Leafhoppers) - Second Supplement to Fascicle 1 - Membracidae of the General Catalogue of the Hemiptera. Mem. Amer. Entomol. Inst. 60: 1-377.

Recebido em 12.VII.2002; aceito em 04.XI.2002. 